\title{
Perfil sociodemográfico e distribuição territorial dos russos em São Paulo: deslocados de guerra da Europa e refugiados da China após a Segunda Guerra Mundial
}

\author{
Svetlana Ruseishvili
}

0 presente artigo tem por objetivo investigar as principais características de dois grupos de russos vindos ao Estado de São Paulo após a Segunda Guerra Mundial: os deslocados de guerra provenientes dos acampamentos para os deslocados na Europa; e os refugiados russos procedentes da China. Para isso foram realizadas uma sistematização e análise dos dados contidos no banco de dados sobre os deslocados de guerra em São Paulo, consolidado por Salles et al. (2013). A pesquisa revelou que a política brasileira da admissão dos deslocados de guerra enquanto mão de obra industrial teve seu impacto direto no perfil da população russa selecionada para imigrar ao país, que se dirigiu predominantemente à capital paulista. Os refugiados russos da China apresentavam perfil demográfico e social distinto, sendo um grupo com maior parcela de mulheres e crianças e empregado no setor de serviços. As características profissionais dos dois grupos determinaram sua distribuição pelos bairros de São Paulo. Enquanto os deslocados de guerra da Europa se dirigiram para os bairros periféricos e industriais, os russos da China instalaram-se nos bairros mais próximos ao centro da cidade.

Palavras-chave: Deslocados de guerra. Russos. Pós-Segunda Guerra Mundial. São Paulo. Imigração.

\footnotetext{
*Universidade de São Paulo (USP), São Paulo-SP, Brasil (s.ruseishvili@gmail.com).
} 


\section{Introdução}

Após o término da Segunda Guerra Mundial, os soviéticos eram uma das nacionalidades mais populosas entre os refugiados na Europa. Naturalmente, uma parte deles era de origem militar: soldados soviéticos da Frente Oriental, prisioneiros de guerra e de campos de concentração nazistas, colaboracionistas e desertores. Mas havia também um grande número de civis: refugiados e os chamados "deslocados de guerra" - pessoas que haviam sido deportadas compulsoriamente, sem ter tido a intenção de deixar seu país. 0 demógrafo americano de origem russa, Eugene $\operatorname{Kulischer}^{1}$ (1949, p. 172), estima que a Organização Internacional para os Refugiados (OIR), constituída em 20 de agosto de 1948, assistia, ao fim da guerra, a cerca de 1.400 .000 pessoas na Europa, das quais:

[...] 875000 refugiados e deslocados de guerra na Europa, 150 mil refugiados russos que permaneciam na Europa desde o término da Primeira Guerra Mundial, 80 mil refugiados armênios, 120 mil refugiados judeus da Alemanha, Áustria e Tchecoslováquia, 200 mil refugiados espanhóis. [...] Esse número inclui cerca de 30 mil refugiados russos da Primeira Guerra Mundial que foram novamente deslocados pela Segunda Guerra Mundial dos países receptores da Europa do Leste.

Assim como após a Primeira Guerra Mundial, a principal estratégia dos países europeus e da OIR para resolver o problema dos refugiados e deslocados era o repatriamento. Conforme a exigência do governo da URSS na Conferência de Yalta, os países aliados se comprometeram a repatriar todos os civis e militares que possuíssem o passaporte soviético desde 1939. Entretanto, na prática, muitos grupos entre os deslocados, principalmente dentre os soviéticos, não eram repatriáveis. Alguns militares temiam perseguição do governo de Stálin por ter sido prisioneiro ou ter passado tempo demasiadamente longo fora das fronteiras soviéticas. Com os refugiados e deslocados civis a situação era ainda mais complexa: uns temiam as repressões, outros viam em seu deslocamento uma oportunidade para poder permanecer na Europa. Havia também uma parcela significante de pessoas, e famílias inteiras, de retirantes voluntários, que acompanharam as tropas alemãs durante a retirada dos territórios soviéticos, servindo-se desse deslocamento como a única chance de sair do país. A complexidade e o número de populações não repatriáveis na Europa pós-guerra eram tão significantes, que o último acampamento organizado para abrigar os deslocados de guerra na Alemanha fechou somente em 1957, ou seja, 12 anos após o término do conflito na Europa. ${ }^{2}$ Estima-se que, em dezembro de 1946, havia na Europa cerca de 700 mil deslocados não repatriáveis (NEIVA, 1949, p. 40). A crescente influência da URSS na Europa, que pressionava os países europeus a repatriar seus cidadãos à força, combinada com a crise habitacional e econômica, fez com que as organizações internacionais

\footnotetext{
1 Vale ressaltar que, conforme a sua afirmação, foi ele quem, “em um estudo preparado para a Organização Internacional de Trabalho em 1943", concebeu o termo "displacement of population" - deslocamento populacional - "com objetivo de abranger todos tipos de deslocamentos populacionais gerados pela guerra” (KULISCHER, 1949, p. 169).

2 Guide to the Displaced Persons Camps and Centers Photograph Collection; Disponivel em: 〈http://findingaids.cjh. org/?pID=2262096\#a2〉. Acesso em 02 set. 2015.
} 
responsáveis pela solução da crise dos deslocados adotassem uma nova estratégia: a de reassentamento para os países norte e sul-americanos e para a Austrália (MARRUS, 1985).

Após alguns debates públicos sobre adesão ou não do Brasil aos acordos internacionais acerca do recebimento dos refugiados e deslocados de guerra (KOIFMAN, 2012; CAMPOS, 2015; SALLES, 2007; RUSEISHVILI, 2016), o governo brasileiro tomou a decisão de admitir no seu território os deslocados de guerra da Europa. A política do recebimento dessas populações foi motivada, em grande parte, pelo desejo de atração ao país da mão de obra qualificada para as atividades industriais nos crescentes centros urbanos. Ao mesmo tempo, como aponta Salles (2007, p. 118), os trabalhadores capacitados continuavam a ser direcionados também para o campo, onde as novas tecnologias de produção agrícola exigiam cada vez mais mão de obra qualificada.

\section{Deslocados de guerra e refugiados russos da China em São Paulo. Apresentação do corpus de dados}

Como resultado, entre julho de 1947 e final da década de 1950, o Brasil recebeu grande número de deslocados de guerra de diversas nacionalidades. Moreira (2013, p. 20) observa que uma estimativa com precisão dificilmente pode ser feita:

Os números de refugiados recebidos pelo Brasil são de difícil precisão. A estatística apresentada pela delegação brasileira na OIR aponta, ao final das atividades da organização, o total de 21.603, entre 10 de julho de 1947 e 31 de julho de 1949. A estimativa do chefe da missão na OIR, datada de 1952, menciona quase 29.000 deslocados de guerra colocados no país. Os dados trazidos pelo chefe do Departamento Econômico e Consular do MRE se referem ao ingresso de 44.000 descolados de guerra entre 1947 e 1950. Por outro lado, de acordo com documento emitido pelo ACNUR, o Brasil teria acolhido 43.811 refugiados de 1948 a 1959, provenientes dos seguintes países: Polônia, Rússia, Ucrânia, Tchecoslováquia, Hungria, Romênia, Bulgária e lugoslávia.

Resumindo, cerca de 21.000 deslocados de guerra da Europa foram recebidos pelo Brasil, entre 1947 e 1949, e cerca de 43.000 até o final dos anos 1950. Na segunda metade da década de 1950, o país recebeu também alguns refugiados russos da China. Conforme a declaração do então presidente do Instituto Nacional de Imigração e Colonização dada ao jornal carioca Correio da Manhã, em 9 de junho de 1959, estimou-se que ao longo da década de 1950 o país recebeu 3.416 "refugiados [russos] brancos da China" (CAMPOS, 2015, p. 398).

Contudo, os russos da China vieram em número maior do que aquele contemplado pelos registros de entrada de refugiados. A condição migratória dos russos da China possuía algumas especificidades históricas, em decorrência das quais a maioria dessas pessoas veio ao Brasil na condição de imigrantes, com visto concedido pelo consulado brasileiro em Hong Kong, conforme o artigo 9 do Decreto-lei n. 7.967 de 1945. Desde a guerra civil russa, a China, principalmente a região da cidade Harbin, no nordeste do país perto da fronteira com a Rússia, abrigou cerca de 100 mil russos. Entre eles havia 
tanto refugiados apátridas, que fugiram do regime comunista, quanto cidadãos soviéticos que trabalhavam na construção do trecho Trans-manchuriano da Ferrovia Transiberiana. Além deles, havia também imigrantes e colonos russos que saíram da Rússia antes de 1917 e também aqueles que se tornaram cidadãos chineses. Até a Revolução Comunista Chinesa, os russos possuíam liberdade em exercer atividades profissionais, inclusive em seu próprio idioma, e usufruíam de uma grande autonomia por parte do governo chinês, mesmo sendo apátridas ou de cidadania soviética. Contudo, após a fundação da República Popular da China, em 1949, com a massiva nacionalização da indústria e do comércio, o acesso aos empregos foi cortado para os cidadãos de outros países e para os apátridas. Entretanto, o governo chinês não impedia a emigração dessa população para outros países (MOUSTAFINE, 2010, p. 153). Finalmente, na segunda metade da década de 1950, os russos foram postos diante de uma escolha: regressar à URSS ou deixar a China. Devido às cotas nacionais já adotadas naquele momento pelo governo dos Estados Unidos, os principais destinos para reassentamento desses migrantes eram países da América do Sul e Austrália. Depois da extinção da Organização Internacional para os Refugiados, em 1952, o status de refugiados foi assegurado para esses russos pelo regulamento da seção oriental do Alto Comissariado pelos refugiados das Nações Unidas, com sede em Hong Kong. ${ }^{3}$ Porém, na maioria dos casos, o reassentamento não era coletivo, ou seja, não era feito nos padrões de reassentamentos dos deslocados de guerra da Europa. Em sua maioria, para sair da China, o refugiado russo obtinha o certificado de viagem emitido pela agência da ONU e com ele apresentava-se ao Consulado brasileiro em Hong Kong para solicitar um visto permanente. $\mathrm{Na}$ chegada ao Brasil, ele não era obrigado a passar pela Hospedaria do Imigrante e podia dirigir-se diretamente ao local de moradia ou emprego.

0 destino das embarcações com os refugiados e deslocados organizadas na Europa pela OIR era o porto do Rio de Janeiro. Posteriormente, cerca de metade dos imigrantes dirigia-se ao Estado de São Paulo (SALLES, 2013, p. 8). Os pesquisadores explicam essa atratividade do Estado de São Paulo pela crescente modernização do parque industrial paulista, assim como pelo crescimento da demanda de mão de obra qualificada nessas indústrias.

Salles (2004, p. 13), citando os dados do Boletim do Departamento de Imigração e Colonização, aponta que entre os 22.574 deslocados que passaram pela Hospedaria de Campo Limpo em São Paulo em 1947, 1948 e 1949, 855 eram de cidadania soviética e 867 eram apátridas. Outra fonte aponta que, entre maio de 1947 e agosto de 1949, entraram no Estado de São Paulo 760 russos, 808 apátridas, 2.963 poloneses e 1.080 ucranianos. ${ }^{4}$

\footnotetext{
${ }^{3}$ Acerca da história de imigração russa na China após a revolução bolchevique, ver Ruseishvili (2016, p. 85-91).

4 “Quadro demonstrativo dos DPs entrados no Estado de São Paulo de 16/05/1947 à 31/08/1949, segundo a nacionalidade”. Dossiê 41 Z-78-30. Deops/APESP-SP.
} 
Para reconstruir o perfil sociodemográfico desses refugiados, foram sistematizadas e analisadas as informações consolidadas no banco de dados POS2WAR $^{5}$ a partir dos documentos localizados no Memorial do Imigrante em São Paulo, ao longo do período de 2003 a 2008 (SALLES et al., 2013; PAIVA, 2007; SALLES, 2004; BASTOS; SALLES, 2014).

0 banco de dados reúne fichas individuais de cada imigrante, sistematizadas em 45 campos, referentes a nacionalidade, naturalidade, origem, sexo, idade, estado civil, procedência, destino, posição familiar (separando o chefe de família dos dependentes), profissão, empresa contratadora, residência, data de chegada, entre outros (BASTOS; SALLES, 2014, p. 158).

Conforme Bastos e Salles (2014), entre os 18.369 registros de ingressos no período de 1947 a 1951, os poloneses eram o maior grupo entre 74 nacionalidades presentes na população de deslocados de guerra que tiveram como destino a cidade de São Paulo. Além disso, as autoras apontam que:

[...] 19\% dos registros encontram-se sem identificação da nacionalidade, o que resulta, provavelmente, de erro da digitação, omissão do documento ou ainda trata-se de imigrantes indocumentados, que preferiam que sua origem fosse ignorada. Os apátridas totalizam $11 \%$ dos ingressos e constituem o terceiro maior grupo, seguidos pelos ucranianos ( $9 \%$ ). Com $6 \%$ destacam- se os húngaros, iugoslavos e russos; com $3 \%$ os de nacionalidades letã, italiana e lituana; com $2 \%$ os de nacionalidades checoslovena e romena e com $1 \%$ os alemães, holandeses, estonianos e armênios. Com menos de $1 \%$ estão os de nacionalidades búlgara, austríaca, grega, portuguesa, espanhola, japonesa, brasileira, croata, colombiana, albanesa, turca, belga, chinesa, estadunidense, finlandesa, georgiana, libanesa, sueca e suíça. (BASTOS; SALLES, 2014, p. 158)

Entre os imigrantes de origem russa, contemplados pelo banco, havia tanto os deslocados de guerra provenientes da Europa quanto refugiados russos vindos da China, ingressos no Brasil principalmente entre 1953 e $1958 .{ }^{6}$ Além disso, um número significativo dos russos figura nos registros de entrada dos estrangeiros no Brasil como apátridas. Enquanto os chefes de família que foram registrados como "russos" totalizam 500 pessoas, os imigrantes fichados como "apátridas" contam com 1.175 registros. Para localizar entre eles os indivíduos de origem russa, precisou-se realizar uma análise complementar de cada ficha individual da população registrada como "apátrida".

O método de identificação dos indivíduos de origem ou procedência russa baseou-se no cruzamento dos dados sobre o local de naturalidade do indivíduo com o seu sobrenome e/ou nomes de seus genitores. Dessa maneira, entre todas as fichas relativas aos chefes de família "apátridas", foram marcadas aquelas que continham indícios de que o

\footnotetext{
${ }^{5}$ POS2WAR. Projeto Fluxos Migratórios e Industrialização em São Paulo (Fapesp, 2003 a 2006). Observatório das Migrações em São Paulo (Nepo/Unicamp - Fapesp/CNPq).

${ }^{6}$ Considerando que os imigrantes da China, que ingressavam no Brasil com o visto permanente, não eram obrigados a passar - e frequentemente não o faziam - pela Hospedaria de Imigrante, o número de imigrantes russos da China registrado pelo banco de dados é certamente inferior ao número estimado pelas autoridades brasileiras, referidas acima. Contudo, sua presença no banco de dados permite incluir essa população na análise de perfil socioprofissional dos imigrantes do período pós-guerra e rastrear suas convergências e diferenças em relação aos imigrantes russos da Europa.
} 
indivíduo em questão era de origem russa. Foram escolhidos os seguintes "marcadores" de origem/nacionalidade russa:

- no campo "naturalidade" do registro consta "Rússia";

- no campo "naturalidade" do registro consta nome de uma cidade - nesse caso, verificava-se o pertencimento da cidade aos territórios da URSS no momento do início da Segunda Guerra Mundial;

- no campo "naturalidade" do registro consta nome de uma cidade localizada nos territórios da fronteira oeste da URSS, etnicamente muito heterogêneos - analisavam-se o sobrenome do indivíduo e os nomes e sobrenomes de seus genitores; ${ }^{7}$

- no campo “naturalidade” não há informações - deduzia-se a origem do indivíduo pelo sobrenome/nome ou sobrenome dos genitores.

Como resultado, dos 1.175 registros de apátridas, foram selecionadas 420 fichas de chefes de família de origem russa. Tendo em vista que, na maioria dos casos, a nacionalidade do indivíduo foi definida na própria ficha do registro, é possível considerar que a amostra resultante é suficientemente representativa, embora o método utilizado na sistematização possa deixar uma margem de imprecisão. No final, do corpus total dos dados primários, foi selecionado para a análise o conjunto de fichas de chefes de famílias "russos" e "russos-apátridas".

Como observado anteriormente, os números resultantes dessa análise não podem ser compreendidos como absolutos. Contudo, a possibilidade de cruzar tipos variados de informações sobre o imigrante permite obter um retrato socioprofissional daqueles russos que ingressaram no Brasil na condição de refugiados e deslocados de guerra e que passaram pelas autoridades de imigração do Estado de São Paulo. Entender o perfil da população em questão facilita a compreensão dos processos de sua adaptação tanto à nova ordem social em solo brasileiro quanto às relações já estabelecidas no país pelos russos ingressos antes da Segunda Guerra Mundial.

\section{Composição familiar e características etárias e de gênero}

Chegados em São Paulo entre 1947 e o final da década de 1950, os imigrantes de origem russa contavam 1.842 pessoas, sendo 920 chefes de família e 922 dependentes. O Gráfico 1 demonstra a dinâmica do ingresso desses imigrantes no Brasil no período após Segunda Guerra Mundial.

\footnotetext{
${ }^{7}$ Parte-se do pressuposto de que é possível identificar a origem étnica do indivíduo pelo seu sobrenome e nome. Para os povos eslavos, a fonética de nomes varia de acordo com o idioma. Por exemplo, o nome russo Mikhail escreve-se Mikhailo em seu variante ucraniano. 0 mesmo é válido para os sobrenomes: o russo Ivanov seria Ivanenko em ucraniano, por exemplo. Embora esse critério abra espaço para uma eventual imprecisão, não foram numerosos os casos controversos que precisariam desse critério de seleção.
} 
GRÁFICO 1

Imigrantes russos ingressos no Estado de São Paulo, por gênero - 1924-1964

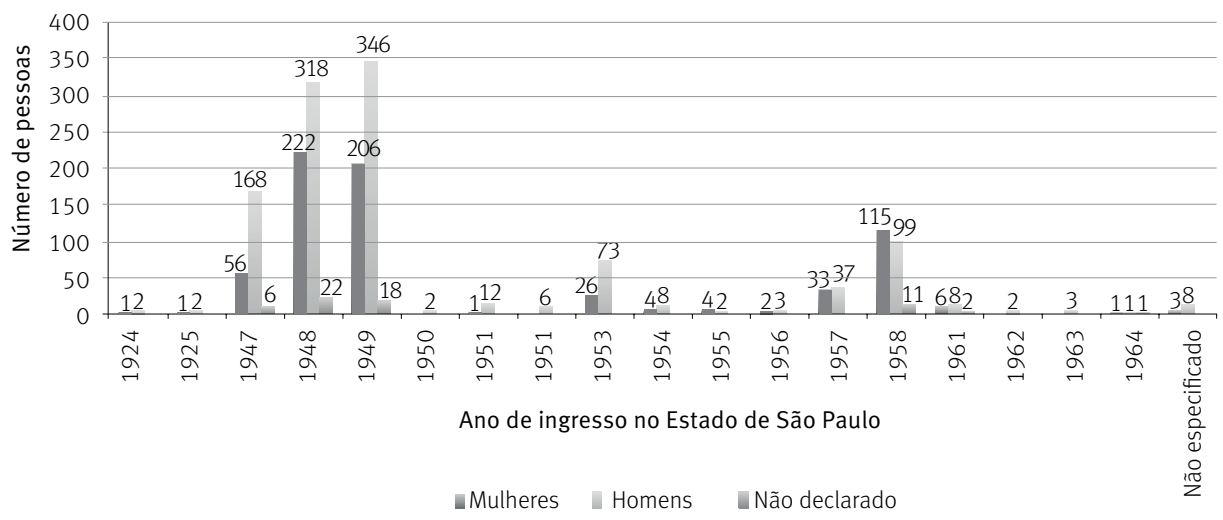

Fonte: POS2WAR. Projeto Fluxos Migratórios e Industrialização em São Paulo (Fapesp, 2003 a 2006). Observatório das Migrações em São Paulo (Nepo/Unicamp - Fapesp/CNPq).

Maior número de entradas de russos registrou-se em 1947, 1948 e 1949, sendo que nos anos seguintes a quantidade diminuiu significativamente. 0 ano de 1952 marca a extinção da OIR e sua substituição pelo Comitê Intergovernamental para as Migrações Europeias (Cime), que passou a organizar as entradas de refugiados no Brasil (BASTOS; SALLES, p. 158). Dessa maneira, observa-se que os refugiados russos eram realocados da Europa ao Brasil, principalmente, pelos esforços da Organização Internacional para os Refugiados, enquanto a acolhida dos russos da China se deu por meio de acordo do governo brasileiro com o Cime.

Na medida que a década de 1940 foi marcada pela vinda dos russos da Europa, nos anos 1950 ocorreu o apogeu do ingresso dos russos da China, com o maior fluxo registrado em 1957 e 1958. É preciso ressaltar que justamente nesses anos observa-se um desequilíbrio entre o número de ingressos homens e o de mulheres: diferentemente da década de 1940, as mulheres ingressaram quase na mesma proporção que os homens. Provavelmente, essa alteração foi consequência das características demográficas específicas dos refugiados russos na China, entre os quais a população feminina teve protagonismo no processo migratório.

Em geral, entre os 920 imigrantes russos cadastrados pelos agentes brasileiros como responsáveis pela família, a maioria compunha-se de homens: 849 contra 71 mulheres. Já a população dos dependentes era predominantemente feminina: 611 mulheres e 251 homens. Entretanto, como abordado anteriormente, a proporção de mulheres entre os responsáveis foi maior para os russos vindos da China: $18 \%$ do total dos responsáveis (contra $8 \%$ das mulheres chefes de família procedentes da Rússia). A legislação brasileira que estabelecia os critérios de seleção dos deslocados de guerra exigia a entrada no país de famílias completas, sendo que as mulheres vindas sozinhas eram potencialmente suspeitas (NEIVA, 1949; CAMPOS, 2015; KOIFMAN, 2012). Em compensação, os russos vindos 
da China não foram sujeitos aos critérios específicos de seleção por parte dos consulados brasileiros, o que possibilitou a vinda de grande número de famílias dirigidas por mulheres, viúvas ou solteiras, acompanhadas por filhos e solitárias.

De um modo geral, a maioria das famílias de imigrantes russos do pós-guerra era composta por um homem, cadastrado como chefe responsável, sua esposa e seus filhos ou enteados, raramente acompanhados pelos demais membros da família como sogros, irmãos ou pais. Entre 922 parentes ingressos como dependentes, o banco de dados registra 352 esposas, 466 filhos, 25 mães, 21 enteados(as), 14 sogros(as), 12 irmãs(os), sete pais, seis sobrinhos(as), cinco netos(as), quatro noras, três cunhados(as), uma tia, e seis pessoas que não definiram seu status familiar.

No que se refere à idade dos indivíduos no momento do ingresso no Brasil, apenas 604 chefes de família declararam sua idade e 318 deixaram o campo em branco. Ao consolidar os dados sobre os primeiros, constata-se que o grupo etário mais numeroso correspondia ao de 30-49 anos: 67\% dos indivíduos com idade declarada. Como já foi observado, o principal objetivo de políticas migratórias brasileiras após a Segunda Guerra Mundial era completar o estoque de mão de obra para a indústria e agricultura. Por essa razão, a legislação brasileira dava preferência aos indivíduos na idade produtiva. Comparando os chefes de família russos vindos da Europa com os da China, verifica-se que a idade média dos primeiros é maior do que a dos segundos: $32 \%$ dos deslocados da Europa tinham de 30 a 39 anos e $38 \%$ estavam na faixa de 40 a 49 anos, enquanto para os russos vindos da China estas proporções correspondem a $45 \%$ e $23 \%$, respectivamente, para os dois grupos etários.

Entre os 922 dependentes, apenas 373 possuem sua idade registrada no banco de dados. Entre esses, constata-se grande número de crianças e jovens: 216 pessoas com idade entre 0 e 19 anos. Paralelamente, a proporção geral dos jovens até 29 anos é maior para os ingressos vindos da China $-44 \%$ do total dos imigrantes. Para os imigrantes procedentes da Europa, as crianças e os jovens somavam $37 \%$, enquanto quase a metade dos dependentes pertencia ao grupo etário entre 30 e 49 anos (49\%).

\section{Perfil profissional dos deslocados de guerra e refugiados russos da China em São Paulo}

Conforme discutido anteriormente, os refugiados e deslocados de guerra interessavam ao Brasil, antes de mais nada, em sua função de mão de obra qualificada para os trabalhos na indústria e na agricultura. As exigências da comissão brasileira de seleção eram rigorosas, o que não impedia os candidatos à imigração de omitir suas verdadeiras profissões para se enquadrar no perfil requerido, conforme investigado largamente pela imprensa da época e pela vigilância policial (CAMPOS, 2015; RUSEISHVILI, 2016). 0 banco de dados aponta também para a prática da requalificação profissional, promovida tanto por meio de cursos de reeducação profissional, empreendidos nos acampamentos europeus para os deslocados (SALLES, 2004, p. 563), quanto pela flexibilidade dos próprios empregadores brasileiros, que permitiam requalificação já após a contratação. 
Inserir-se no mercado de trabalho no Brasil era a prioridade de sobrevivência para esses migrantes russos. Naturalmente, muitas vezes isso significava uma desvalorização de suas qualificações. Como aponta Salles (2004, p. 564):

Comparando-se a profissão declarada no passaporte, ou na chegada à Hospedaria, e a $1^{\text {a }}$ profissão ou emprego realmente desempenhado, notou-se uma diferença significativa. Essa diferença provavelmente se deve ao fato de que num primeiro momento de chegada, os imigrantes aceitavam ocupações de operários qualificados e técnicos, mesmo quando possuíam qualificações de nível médio e superior.

A citação aponta para outra propriedade relevante dos dados consolidados no banco de dados: as profissões que constam nas fichas de ingresso são aquelas que os imigrantes declaravam antes de serem efetivamente contratados pelas empresas brasileiras. Isso significa que nem sempre essas declarações correspondiam à real capacitação dos indivíduos: frequentemente, fazer-se passar por operário era uma estratégia para ser aceito a imigrar ao Brasil. Inclusive, a comissão brasileira de seleção dos deslocados lançava mão de várias técnicas e procedimentos para detectar se o pretendente estava omitindo a sua verdadeira ocupação profissional, conforme relatado detalhadamente por Neiva (1949, p. 54-55).

Para análise das informações referentes à profissão declarada dos imigrantes, os dados primários foram agrupados conforme critério de classificação que refletisse a qualificação do trabalhador. Assim, foram criados seis grupos de profissões, segundo o nível de sua qualificação: “operários”, compreendendo ocupações como mecânico, eletricista, ferreiro, pintor, carpinteiro, operário, pedreiro, soldador, serralheiro, entre outras; "técnicos e profissionais de nível médio e superior", tais como engenheiros especializados, topógrafos, desenhistas, químicos, veterinários, enfermeiros, técnicos em laticínios, técnicos em celulose, etc.; “profissões autônomas”, tais como fotógrafos, estudantes, comerciários, motoristas, músicos, barbeiros, interpretes, religiosos, massagistas, etc.; "serviços domésticos", reunindo prendas domésticas e governantas; "serviços e ocupações não qualificados”, como jardineiros, caseiros, vendedores, cozinheiros, zeladores, guarda-livros, cocheiros, dentre outros; e "agricultores".

TABELA 1

Imigrantes russos chefes de família, segundo qualificação profissional declarada Estado de São Paulo - 1947-1958

\begin{tabular}{|c|c|c|}
\hline Qualificação & Número absoluto & $\%$ \\
\hline Agricultor & 41 & 4,0 \\
\hline Serviços domésticos & 21 & 2,0 \\
\hline Autônomo & 51 & 6,0 \\
\hline Não especificada & 204 & 22,0 \\
\hline Operário & 441 & 48,0 \\
\hline Sem qualificação & 35 & 4,0 \\
\hline Técnico; profissional de nível médio ou superior & 127 & 14,0 \\
\hline Total & 920 & 100,0 \\
\hline
\end{tabular}

Fonte: POS2WAR. Projeto Fluxos Migratórios e Industrialização em São Paulo (Fapesp, 2003 a 2006). Observatório das Migrações em São Paulo (Nepo/Unicamp - Fapesp/CNPq). 
A Tabela 1 evidencia que a maior parte dos responsáveis pela família se declarava como trabalhadores industriais (48\%). Entre eles, havia 108 mecânicos, 83 operários de diversas especialidades (de couro, de fiação, de laticínios, têxtil, etc.), 39 carpinteiros, 39 eletricistas e eletromecânicos, 25 pintores, dentre outros.

A demanda por profissionais técnicos e de nível médio e superior proporcionou a seleção de grande número desses especialistas nos campos de refugiados na Europa. No interior dessa mão de obra especializada, o maior interesse foi pelos profissionais em engenharia, de produção têxtil, de celulose e de laticínios, da construção civil e da indústria química. Entre as 127 pessoas agrupadas na categoria "técnico; profissional de nível médio ou superior”, havia 44 pessoas declaradas como técnicos com especialização em diversas áreas da indústria: mineração, óptica, madeiras, construção civil, celulose, elétrica, etc. Entre os 20 profissionais de nível superior, a maioria possuía diploma em engenharia (mecânica, civil, arquitetura, elétrica) e outros seis, em química.

Entre os chefes de família classificados como profissionais autônomos, havia trabalhadores do comércio (quatro comerciantes, dois vendedores e um empresário), prestadores de diferentes serviços (quatro fotógrafos, três motoristas, três barbeiros, dois costureiros, dois guarda-livros, entre outros), trabalhadores de ciência, artes, ensino e religião (11 músicos, dois pintores, dois professores de música, dois professores, quatro estudantes e um religioso).

Entre as ocupações sem qualificação, encontravam-se sete jardineiros, cinco zeladores e guardas noturnos, sete auxiliares de escritório, vendedores ambulantes e outras ocupações, no total de 35 pessoas.

As atividades domésticas eram desenvolvidas quase exclusivamente por mulheres: do total de 21 responsáveis pela família registrados como prendas domésticas, 20 eram mulheres e apenas um homem. Para a população dos dependentes, com predominância das mulheres, as ocupações nos variados serviços domésticos totalizavam $38 \%$ das profissões declaradas: 163 pessoas (Tabela 2). Entre o total de 295 mulheres ingressas como dependentes que declararam sua ocupação, 157 (53\%) se registraram como "prendas domésticas” ou "empregadas domésticas". Quanto a outras ocupações, 32 mulheres foram registradas como costureiras, tecelãs e aprendizes, 27 como estudantes, 23 como agricultores, 15 nos serviços de escritório (secretária, datilógrafa, estenógrafa, auxiliar de escritório, etc.), seis em profissões técnicas e de nível superior (médica farmacêutica, desenhista, enfermeira e dentista), sete operárias, quatro cabeleireiras, duas professoras, uma pintora, dentre outras. Como vimos, as ocupações femininas eram predominantemente sem qualificação específica, circunscritas, sobretudo, ao universo de serviços domésticos, enquanto as ocupações dos homens eram localizadas no mercado de trabalho industrial.

Embora as instruções sobre a seleção de imigrantes nos acampamentos de refugiados orientassem a comissão brasileira a manter a proporção de $70 \%$ de agricultores e $30 \%$ de técnicos especializados (CAMPOS, 2015, p. 362), na prática essa orientação nem 
sempre foi cumprida. Para os imigrantes russos vindos para São Paulo cuja ocupação profissional consta nos registros analisados, $6 \%$ eram agricultores e $94 \%$ possuíam ocupações urbanas. No total, os russos registrados como agricultores correspondiam a apenas 41 chefes de família e 33 dependentes. Entre os chefes de família, dois foram reclassificados como mecânicos de tratores e a maioria dirigiu-se às fazendas no interior dos estados de São Paulo, Minas Gerais, Paraná e Goiás. Apenas um chefe de família registrado como agricultor provinha da China. Entre os 33 dependentes, oito pessoas não foram efetivamente empregadas na agricultura: duas esposas registraram seu primeiro emprego nos serviços domésticos na cidade e seis outros dependentes, todos homens, foram requalificados para trabalhos na indústria na função de mecânicos, montador, carpinteiro e operário.

TABELA 2

Imigrantes russos dependentes, segundo qualificação profissional declarada Estado de São Paulo - 1947-1958

\begin{tabular}{|c|c|c|}
\hline Qualificação & Número absoluto & $\%$ \\
\hline Agricultor & 33 & 4,0 \\
\hline Serviços domésticos & 163 & 18,0 \\
\hline Autônomo & 57 & 6,0 \\
\hline Não especificada & 493 & 53,0 \\
\hline Operário & 93 & 10,0 \\
\hline Sem qualificação & 17 & 2,0 \\
\hline Técnico; profissional de nível médio ou superior & 8 & 1,0 \\
\hline Estudante/aprendiz & 58 & 6,0 \\
\hline Total & 922 & 100,0 \\
\hline
\end{tabular}

Fonte: POS2WAR. Projeto Fluxos Migratórios e Industrialização em São Paulo, (Fapesp, 2003 a 2006). Observatório das Migrações em São Paulo (Nepo/Unicamp - Fapesp/CNPq).

\section{Distribuição territorial dos deslocados de guerra e refugiados russos da China no Estado e na cidade de São Paulo}

As fichas pessoais que deram origem ao banco de dados contêm informações sobre a primeira residência do imigrante e sua família, o local do primeiro emprego e, ocasionalmente, informações sobre alteração do endereço de residência, de emprego ou acerca de solicitação do visto de saída do país. Esse conjunto de dados permite localizar territorialmente os imigrantes do pós-guerra no Estado e na cidade de São Paulo, além de mapear a presença de cada uma das nacionalidades no tecido urbano, articulando o endereço de sua residência ao endereço de seu trabalho, como feito por Salles (2004, p. 565).

Para os imigrantes de origem russa foram consolidados, sobretudo, os dados sobre a residência de cada família. Importante ressaltar que a mobilidade residencial foi bastante alta nos primeiros anos de sua instalação no Brasil. Geralmente, as primeiras residências 
eram de grande precariedade, devido à instabilidade profissional e financeira da família na cidade. Não raro, essas residências localizavam-se nas regiões próximas aos locais de trabalho e foram encontradas por meio da mobilização de redes intracomunitárias. Salles et al. (2013, p. 21) apontam para os seguintes critérios de distribuição dos imigrantes após a Segunda Guerra pelos bairros de São Paulo:

[...] há toda uma conjuntura própria aos bairros industriais, terrenos e alugueis mais baratos, um sistema de transporte razoável tanto nas beiras de ferrovia quanto nas rodovias e quanto ao transporte urbano, o bonde e depois o ônibus, etc. 0 que, entretanto, é mais significativo na escolha de locais de moradia, é o fato de que anteriormente, já havia imigrantes das mesmas nacionalidades concentradas nesses bairros.

Embora a primeira moradia fosse um local provisório, sua localização permite mapear a distribuição geral dos imigrantes russos pelos municípios do Estado de São Paulo e pelos bairros da capital. Ela indica os locais de concentração tanto de seus conterrâneos quanto das classes laboriosas em geral na cidade após a Segunda Guerra.

Conforme mostra a Tabela 3, os municípios do Estado de São Paulo com maior agrupamento de imigrantes russos eram localizados na proximidade da capital. Assim, entre as 1.229 pessoas com indicação da primeira residência, a maioria (77\%, 949 imigrantes) se estabeleceu na cidade de São Paulo. São Caetano do Sul, subúrbio agrícola no começo do século e um grande centro industrial depois da guerra, recebeu 72 imigrantes russos, $6 \%$ do total. Santo André, outro município vizinho da capital com grande número de indústrias instaladas, recebeu 34 imigrantes russos após a guerra. Outro polo importante de concentração desses imigrantes localiza-se entre municípios limítrofes com a cidade de São Paulo, no oeste: Osasco, com 60 casos, Carapicuíba, com 12, e Jundiaí, com 10.

Langenbuch (1971) aponta que as décadas de 1930-1940 foram marcadas pela aproximação dos subúrbios industriais com os bairros do município de São Paulo. Esse processo ganhou mais destaque na região sudeste da capital, com a junção dos municípios de São Caetano, São Bernardo e Santo André com os novos loteamentos residenciais surgidos nos bairros Vila Bela, Vila Alpina, dentre outros.

Outro polo de aproximação e integração dos territórios suburbanos ao tecido urbano de São Paulo foram os bairros na divisa com Santo Amaro:

Santo Amaro foi o município mais abrangido pelo "cinturão de loteamentos residenciais suburbanos". Indianópolis se estendia até a divisa, através de seu prolongamento Vila Helena, e no município vizinho se sucediam uma série de loteamentos, que uniam São Paulo e Santo Amaro, destacando-se Campo Belo e Brooklin Paulista (LANGENBUCH, 1971, p. 138.). 
TABELA 3

Distribuição dos imigrantes russos, segundo município da primeira residência Estado de São Paulo - 1947-1958

\begin{tabular}{|c|c|}
\hline Municípios & Total \\
\hline Amparo & 6 \\
\hline Assis & 1 \\
\hline Batatuba & 3 \\
\hline Bragança Paulista & 1 \\
\hline Brás Cubas & 2 \\
\hline Campinas & 9 \\
\hline Campo Limpo & 5 \\
\hline Caraguatatuba & 1 \\
\hline Carapicuíba & 12 \\
\hline Cubatão & 2 \\
\hline Eldorado & 1 \\
\hline Garça & 1 \\
\hline Goiás, GO & 5 \\
\hline Guarulhos & 15 \\
\hline Indiana & 1 \\
\hline Itapuí & 1 \\
\hline Jundiaí & 10 \\
\hline Limeira & 5 \\
\hline Lins & 3 \\
\hline Mogi das Cruzes & 8 \\
\hline Osasco & 60 \\
\hline Ponta Grossa, PA & 2 \\
\hline Rincão & 3 \\
\hline Rio Claro & 1 \\
\hline São Bernardo do Campo & 5 \\
\hline Salto & 2 \\
\hline Santo André & 34 \\
\hline Santos & 5 \\
\hline São Caetano do Sul & 72 \\
\hline São Paulo & 949 \\
\hline Suzano & 2 \\
\hline Taubaté & 1 \\
\hline Terra Roxa & 1 \\
\hline Não especificado & 613 \\
\hline Total & 1.842 \\
\hline
\end{tabular}

Fonte: POS2WAR. Projeto Fluxos Migratórios e Industrialização em São Paulo (Fapesp, 2003 a 2006). Observatório das Migrações em São Paulo (Nepo/Unicamp - Fapesp/CNPq).

Como pode se observar na Tabela 4, os imigrantes russos vindos após a guerra concentravam-se, principalmente, nos bairros operários nos arredores de grandes indústrias, que, conforme aponta Langenbuch (1971, p. 139-146), continuavam sendo “comandada[s] pela ferrovia". 0 mesmo autor indica que 
[...] a intensa implantação industrial, ao longo das ferrovias, convidava os operários a se estabelecerem em torno das estações ferroviárias situadas fora da cidade, onde poderiam adquirir terrenos, ou alugar casas, a preços mais razoáveis - enquanto se beneficiavam de um meio de transporte rápido e de preço acessível entre local de residência e local de trabalho (LANGENBUCH, 1971, p. 135).

Os principais polos industriais da época concentravam-se ao longo da ferrovia SantosJundiaí, compreendendo os três municípios suburbanos - São Caetano, São Bernardo e Santo André - e os bairros paulistanos na várzea do rio Tamanduateí. Outro polo industrial se instalou na região oeste da cidade, entre Osasco e Vila Leopoldina.

TABELA 4

Distribuição dos imigrantes russos, segundo bairros da primeira residência Município de São Paulo - 1947-1958

\begin{tabular}{|c|c|c|}
\hline Bairros & Total & $\%$ do total dos especificados \\
\hline Água Branca & 11 & 1,04 \\
\hline Barra Funda, Lapa & 40 & 3,80 \\
\hline Bela Vista & 12 & 1,14 \\
\hline Campo Belo & 10 & 0,95 \\
\hline Centro & 10 & 0,95 \\
\hline Indianópolis & 41 & 3,89 \\
\hline Ipiranga & 31 & 2,94 \\
\hline Liberdade & 12 & 1,14 \\
\hline Moema & 21 & 1,99 \\
\hline Osasco & 10 & 0,95 \\
\hline Penha & 11 & 1,04 \\
\hline Pinheiros & 11 & 1,04 \\
\hline Santo Amaro & 47 & 4,46 \\
\hline Vila Alpina & 34 & 3,23 \\
\hline Vila Anastácio & 48 & 4,56 \\
\hline Vila Bela & 153 & 14,53 \\
\hline Vila Hamburguesa & 11 & 1,04 \\
\hline Vila Ipojuca & 11 & 1,04 \\
\hline Vila Leopoldina & 25 & 2,37 \\
\hline Vila Maria & 26 & 2,47 \\
\hline Vila Mariana & 13 & 1,23 \\
\hline Vila Prudente & 17 & 1,61 \\
\hline Vila Santa Clara & 10 & 0,95 \\
\hline Vila São José & 10 & 0,95 \\
\hline Vila Zelina & 163 & 15,48 \\
\hline Outros & 265 & 25,17 \\
\hline Não especificados & 789 & 0,00 \\
\hline Total & 1.842 & \\
\hline Total especificados & 1.053 & 100,00 \\
\hline
\end{tabular}

Fonte: POS2WAR. Projeto Fluxos Migratórios e Industrialização em São Paulo (Fapesp, 2003 a 2006). Observatório das Migrações em São Paulo (Nepo/Unicamp - Fapesp/CNPq). 
Dessa maneira, observa-se que os imigrantes russos analisados residiam, principalmente, na zona sudeste da capital (41,6\%), compreendendo as "vilas" nos morros do rio Tamanduateí e os três municípios suburbanos industriais, na zona sul $(18,6 \%)$, englobando os bairros Campo Belo, Indianópolis, Moema, Jabaquara, Pedreira, Santo Amaro e outros, e na zona oeste (15,2\%), nos bairros Vila Leopoldina, Vila Anastácio, Lapa, Pinheiros e municípios de Osasco e Carapicuíba.

A concentração dos russos em certas localidades propiciou a organização da vida comunitária marcada por dispersão e segregação. Os recém-chegados que se instalavam em proximidade com uma comunidade russa já organizada utilizavam seus estabelecimentos existentes, sobretudo as paróquias religiosas. A região a leste e sudeste da capital, como São Caetano do Sul, Santo André e bairros como Vila Bela, Vila Zelina, Vila Prudente, dentre outros, era servida pela já existente, desde 1931, paróquia ortodoxa russa de Santíssima Trindade, localizada na Vila Alpina. Já os imigrantes que passaram a residir a oeste organizaram sua própria paróquia ortodoxa em Carapicuíba, com igreja construída em 1949 (VOROBIEFF, 2006, p. 79-81). Na cidade de São Paulo, além da Catedral Ortodoxa Russa, funcionando desde 1939, na região central, e da igreja da Vila Alpina já mencionada, foram construídas, após a guerra, mais duas igrejas em Moema e Indianópolis (1952), uma igreja nas proximidades da represa Billings, no bairro Pedreira (1952), e outra na Vila Zelina (1962), além de uma paróquia russa organizada pela Igreja Católica, em 1947, no bairro Ipiranga para servir aos imigrantes da Segunda Guerra e da China (VOROBIEFF, 2006; RUSEISHVILI, 2016).

Entretanto, o maior fluxo desses imigrantes do pós-guerra dirigiu-se aos subúrbios industriais ao longo do rio Tamanduateí. Os bairros Vila Prudente, Vila Zelina, Vila Bela, Vila Alpina e os arredores já eram marcados pela presença de imigrantes do antigo Império russo desde os anos 1920-1930. Com a chegada da nova leva migratória do pós-guerra, as atividades comunitárias se intensificaram consideravelmente. A região ao longo da ferrovia Santos-Jundiaí abrigava grandes indústrias e os bairros operários com grande número de trabalhadores de origem estrangeira surgiam naturalmente em seus entornos. Como ressalta o historiador Nicolau Sevcenko, filho de imigrantes ucranianos vindos após a guerra, os moradores concentravam-se segundo a sua procedência nacional ou idioma, de modo que formavam comunidades linguísticas quase que homogêneas:

Eu cresci lá naquele contexto da zona leste, no bairro da Vila Prudente, num subdistrito chamado Quinta das Paineiras. 0 nome é bonito, mas era um subdistrito industrial. É um enclave que ficava entre a indústria Ford, a indústria Vemag e a indústria General Motors. Era uma área de altíssima industrialização ao longo da várzea do Tamanduateí, porque ele serviu como esteio da estrada de ferro, a Santos-Jundiaí, portanto conexão direta com o Porto de Santos. Foi o que fez com que as indústrias exportadoras se assentassem ao longo da linha do trem, e aí surgiram bairros operários vinculados à população ligada a essas indústrias. A minha família transitou amplamente pelo leste industrial, de início estava na Mooca, daí para a Vila Zelina e depois veio para a Quinta das Paineiras. A razão da migração foi porque originalmente a população eslava estava concentrada na região 
da Mooca. E depois foi progressivamente se ambientando na área mais alta: a Vila Alpina, Vila Zelina, Vila Tolstói; que se encheram daquelas igrejas com torres de estilo oriental, em forma de cabeça de alho. Se você olhasse para qualquer colina mais alta, em cima dela haveria uma igreja com aquela arquitetura típica das igrejas ortodoxas da Europa Oriental; parecia que você estava num trecho da Europa Oriental. A língua mais comum, embora houvesse gente vinda de vários países da Europa Oriental, a língua geral era o russo. Se você não falava russo não conseguia comprar pão ali, o que me fez crer, por muito tempo, que eu estava na Rússia. Cai na realidade, quando fui para a escola e voltei correndo pra minha mãe, chorando e dizendo: "me puseram numa escola de estrangeiros", e pela primeira vez ouvi: “não, estrangeiro é você, estrangeiros somos nós”. ${ }^{8}$

Esse relato destaca que uma das principais motivações para a escolha do local de residência era a falta de domínio do idioma português pelos imigrantes, que consequentemente procuravam se fixar nas regiões de concentração de seus conterrâneos. Isso certamente facilitava a sobrevivência do dia a dia por meio da ativação de redes de vizinhança e de solidariedade, com base na condição compartilhada de migrantes e operários, conforme revelado por outro relato:

Quando chegamos em São Paulo, fomos morar primeiro em Santo André. Era um lugar precário na época: não existia nem rede elétrica, nem água canalizada, nem saneamento básico. Depois nós fomos morar na Vila Bela, frequentávamos a igreja da Vila Alpina e lembro que havia muitos paroquianos. Nós alugávamos um quarto e morávamos em muita precariedade. As vezes, nossos vizinhos traziam leite e pão, porque não tínhamos nem comida. A vida só começou a melhorar quando eu terminei a escola técnica e consegui um emprego como operário na indústria automobilística. Meus país já tinham 50 e 60 anos e não conseguiam achar um emprego. ${ }^{9}$

Como vimos, o local de residência estava diretamente ligado à ocupação do chefe da família, combinado a outros fatores, como o valor de terrenos e imóveis e o local da concentração dos outros imigrantes falantes do mesmo idioma. Dessa maneira, conquanto o destino dos imigrantes empregados nas indústrias fosse as regiões na várzea do rio Tamanduateí e a região de Osasco-Jundiaí, os imigrantes russos da China apresentavam outro perfil socioprofissional que teve impacto na sua distribuição espacial pelos bairros da capital paulista.

Os russos da China provinham na sua maioria de cidades, empregados principalmente no comércio e nos diversos setores de serviços. Já que eles não foram submetidos ao processo de seleção por parte dos representantes brasileiros, como no caso dos deslocados russos da Europa, a maior parte entre eles não era de trabalhadores industriais. Além disso, a forte presença da população feminina, envolvida na prestação de serviços, e os valores imobiliários favoráveis fizeram com que a grande parte desses imigrantes se instalasse nos bairros residenciais próximos ao centro da cidade. Nas décadas de 1950, os bairros Indianópolis, Moema

\footnotetext{
${ }^{8}$ Entrevista de Nicolau Sevcenko concedida a Alvaro Katsuaki Kanasiro e Luis Felipe Kojima Hirano em novembro de 2011. Disponivel em Outras Palavras, 〈http://outraspalavras.net/outrasmidias/destaque-outras-midias/nicolau-sevcenkodesgarrado-e-genial/?utm_source=feedly\&utm_reader=feedly\&utm_medium=rss\&utm_campaign=nicolau-sevcenkodesgarrado-e-genial〉. Acesso em: 16 ago. 2014.

${ }^{9}$ Depoimento colhido em 19 de junho de 2015 em São Paulo (RUSEISHVILI, 2016).
} 
e Mirandópolis passavam por período de crescimento populacional e imobiliário, e ainda ofereciam preços acessíveis para as populações mais desprovidas de recursos (LANGENBUCH, 1971, p. 134). Essa região representou uma concentração massiva de imigrantes russos procedentes da China, que se integravam nos setores de serviços urbanos, serviços domésticos e comércio. Entre 178 imigrantes da China, que constam no banco de dados, 21 declararam sua primeira residência nos bairros de Indianópolis e Mirandópolis, 20 no Jardim Europa, 14 em Santo Amaro, nove no Ipiranga, excluindo 83 sem identificação da residência.

De uma forma geral, a distribuição dos imigrantes russos pelos bairros da cidade de São Paulo demonstra uma tendência geral. Selecionados e admitidos para imigrar ao Brasil, exclusivamente como mão de obra industrial, as condições de sua instalação ficavam marcadas pela condição geral na qual se encontravam as classes operárias na cidade. Do Brás, do Bom Retiro e da Mooca, nos anos 1920, os bairros operários acompanhavam o movimento das indústrias mais ao sul, em direção aos subúrbios outrora agrícolas. Tendo uma interrupção significativa nos novos fluxos migratórios durante o Estado Novo, foram os imigrantes chegados no final do século XIX e começo do século XX que formaram a classe operária paulista, num movimento que Fausto (1991, p. 32) descreve como a dominância da consciência de classe sobre a consciência étnica:

[...] um setor da massa de imigrantes cristalizou-se como classe trabalhadora urbana, em um processo pelo qual se frustrou o projeto de imigrante e se definiu a contradição entre estrangeiro/assalariado, com a dominância do segundo elemento, sem a supressão do primeiro.

Os imigrantes russos vindos para São Paulo após a Segunda Guerra Mundial se encontravam diretamente na condição de operários, inseridos no contexto urbano acompanhando a distribuição da população operária local, embora separados dela pelo desconhecimento do idioma português. Contudo, essa desvantagem era plenamente compensada pela convivência cotidiana com outras famílias de deslocados russos, que exerciam papéis, ao mesmo tempo, de ajuda mútua intracomunitária e de representação diante das associações operárias supranacionais. Foram esses os fatores que propiciaram a maior concentração dos russos em bairros específicos, como apontado anteriormente.

\section{Considerações finais}

A recepção pelo Brasil dos deslocados e refugiados da Europa após a Segunda Guerra Mundial foi fruto da parceria do governo brasileiro com as organizações internacionais para os refugiados. Nessa parceria cada parte era motivada por seus interesses próprios. Os países europeus, por meio da Organização Internacional para os Refugiados e, posteriormente, do Alto Comissariado das Nações Unidas para os Refugiados e Comitê Intergovernamental para as Migrações Europeias, tratavam a questão dos deslocados como excepcional e temporária e pretendiam aliviá-la por meio do reassentamento dessas populações nos países fora do continente. Nesse empreendimento, deslocados de guerra, apátridas e refugiados 
eram metodicamente apresentados aos potenciais países receptores como uma fonte de mão de obra especializada e qualificada, indispensável para o crescimento das economias emergentes. Esse era um argumento fundamental para justificar a recepção de populações potencialmente "indesejáveis" pelo Brasil que tinha acabado de sair de um regime autoritário e hostil às imigrações. Os discursos xenófobos continuavam presentes entre as classes políticas brasileiras, como demonstra Campos (2015) e Koifman (2012, p. 43), e por isso a recepção dos refugiados europeus foi condicionada a uma seleção rigorosa dos indivíduos capacitados, qualificados e aptos aos trabalhos industriais. 0 "material migratório" - termo comumente empregado na documentação oficial da época, que formalizava a ideia de desumanização do imigrante - não elegível para imigração ao Brasil foi descartado com base nos critérios eugênicos e ideológicos, sendo os principais alvos judeus, suspeitos em atividades comunistas, mulheres, idosos e deficientes físicos (RUSEISHVILI, 2016, p. 121-128).

Os indivíduos de origem russa que faziam parte das populações não repatriáveis radicadas na Europa após o fim da Segunda Guerra representavam um contingente bastante oportuno para o governo brasileiro. Geralmente contrários ao governo soviético (já que não desejavam regressar ao seu país de origem), com formação técnica ou superior obtida nos estabelecimentos europeus ou soviéticos, esses russos correspondiam às principais exigências do governo brasileiro. De fato, conforme demonstram os dados analisados anteriormente, a maioria dos russos aceitos para se instalar no Brasil se dirigiu ao parque industrial, localizado predominantemente na capital paulista. Suas características profissionais, de idade e de gênero refletiam a seleção bastante eficiente empreendida pelo governo do Brasil nos acampamentos para os refugiados na Europa. Isso se torna ainda mais visível em comparação com as características socioprofissionais dos russos vindos da China na segunda metade da década de 1950. Sem terem sido submetidos à seleção, eles escaparam das principais exigências do governo brasileiro acerca do perfil dos migrantes e acabaram se inserindo, em São Paulo, nas atividades de serviços, de profissões autônomas e no comércio.

Esse perfil profissional das duas populações de russos em destaque foi o principal critério de sua distribuição pelos bairros da cidade. Os russos da Europa, empregados nas indústrias, se instalaram nos bairros proletários, enquanto os russos provenientes da China buscavam residir em bairros menos afastados do centro de São Paulo, onde era concentrada a sua atividade profissional. Dessa maneira, a sua distribuição urbana foi marcada por duas dinâmicas contraditórias: de um lado, uma concentração segundo o local de procedência e o idioma comum e, de outro, uma segregação territorial segundo a atuação profissional. Essas características proporcionaram uma fragmentação da vida comunitária dos imigrantes russos em São Paulo nos anos 1950-1960.

\section{Referências}

BASTOS, S. R.; SALLES, M. R. R. A imigração polonesa para São Paulo no pós-Segunda Guerra Mundial no quadro das entradas dos “deslocados de guerra": 1947-1951. Revista Brasileira de Estudos de População. v. 31, n. 1, p. 151-167, 2014. 
CAMPOS, G. B. Dois séculos de imigração no Brasil. A construção da imagem e papel social dos estrangeiros pela imprensa entre 1808 e 2015. Tese (Doutorado em Comunicação e Cultura) - Programa de Pós-Graduação em Comunicação e Cultura da Escola de Comunicação da Universidade Federal do Rio de Janeiro (UFRJ), Rio de Janeiro, 2015.

FAUSTO, B. Historiografia de imigração para São Paulo. São Paulo: Editora Sumaré, 1991.

KOIFMAN, F. Imigrante ideal: o Ministério da Justiça e a entrada de estrangeiros no Brasil (19411945). Rio de Janeiro: Civilização Brasileira, 2012.

KULISCHER, E. Displaced persons in the Modern World. Annales of the American Academy of Political and Social Science, v. 262, p. 166-177, Mar. 1949.

LANGENBUCH, J. R. A estruturação da Grande São Paulo. Estudo de geografia urbana. Rio de Janeiro: IBGE, 1971.

MARRUS, M. R. The unwanted: European refugees in the twentieth century. New York: Oxford University Press, 1985.

MOREIRA, J. B. Recepção de refugiados europeus no Brasil do pós-guerra. In: 37 ENCONTRO ANUAL DA ANPOCS. Anais... Águas de Lindóia: Anpocs, 2013.

MOUSTAFIN, M. Russians from China: migrations and identity. International Journal of Diversity in Organizations, Communities and Nations. v. 9, n. 6, p. 173-186, 2010.

NEIVA, A. H. Deslocados de guerra: a verdade sobre sua seleção. Rio de Janeiro: Ed. A Noite, 1949.

PAIVA, O. C. Migrações para São Paulo pós-Segunda Guerra Mundial. Desafios de normatização da diversidade. In:XXIV SIMPÓSIO NACIONAL DE HISTÓRIA. Anais... São Leopoldo: ANPUH, 2007.

RUSEISHVILI, S. Ser russo em São Paulo: os imigrantes russos e a (re)formulação de identidade após a Revolução bolchevique de 1917. Tese (Doutorado em Sociologia) - Programa de Pós-graduação em Sociologia da Faculdade de Filosofia, Letras e Ciências Humanas da Universidade de São Paulo (FFLCH/USP), São Paulo, 2016.

SALLES, M. R. R. Imigração, família e redes sociais: a experiência de "deslocados de guerra", em São Paulo, no pós-Segunda Guerra Mundial. In: XIV ENCONTRO NACIONAL DE ESTUDOS POPULACIONAIS. Anais... Caxambu/MG: Abep, 2004.

A política imigratória brasileira no pós-Segunda Guerra Mundial e os refugiados: uma leitura da Revista de Imigração e Colonização. Cena Internacional, v. 9, n. 2, p. 184-210, 2007.

SALLES, M. R. R.; BASTOS, S.; PAIVA, O.; PERES, R.; BAENINGER, R. (Org.). Imigrantes internacionais no pós-Segunda Guerra Mundial. Campinas: Nepo/Unicamp, 2013 (Coleção Por Dentro do Estado de São Paulo, v. 11).

VOROBIEFF, A. Identidade e memória da comunidade russa na cidade de São Paulo. Dissertação (Mestrado em Geografia Humana) - Departamento de Geografia, Faculdade de Filosofia, Letras e Ciências Humanas da Universidade de São Paulo (FFLCH/USP), São Paulo, 2006.

\section{Sobre a autora}

Svetlana Ruseishvili é doutora em Sociologia pela Universidade de São Paulo, mestre em Sociologia pela École des Hautes Études en Sciences Sociales de Paris e graduada em Sociologia pela Universidade Estatal de Moscou. 


\title{
Endereço para correspondência
}

Rua Martiniano de Carvalho, 599, 11, Bela Vista

01321-001 - São Paulo-SP, Brasil

\begin{abstract}
Social and Professional Profile and Territorial Distribution of Russians in São Paulo: Displaced Persons from Europe and Refugees from China after World War II

The aim of this article is to research the main characteristics of two Russian groups coming to the State of São Paulo after World War II: DPs from Europe and Russian refugees from China. To that end, data contained in the database on DPs in the State of São Paulo, consolidated by Salles et al. (2013), was systematized and analyzed. Research revealed that the Brazilian policy on admission of DPs as industrial workforce had direct impact on the profile of the Russian population selected to immigrate to Brazil, mainly moving to the capital of the State of São Paulo. Russian refugees from China had a different demographic and social profile; the group had the most women and children and employed predominantly in the service sector. The professional characteristics of these two groups determined their distribution in the districts of São Paulo. As Europe's Russian DPs moved to peripheral and industrial districts, Russians from China settled in neighborhoods closer to the city center.
\end{abstract}

Keywords: Displaced persons. Russians. Post-WWII. São Paulo. Immigration.

\section{Resumen}

Perfil socioprofesional y distribución territorial de los rusos en San Pablo: desplazados de guerra de Europa y refugiados de China tras la Segunda Guerra Mundial

El presente artículo tiene como objetivo investigar las principales características de dos grupos de rusos llegados al estado de San Pablo tras la Segunda Guerra Mundial: los desplazados de la guerra provenientes de los campamentos para desplazados de Europa y los refugiados rusos procedentes de China. Para ello sistematizaron y analizaron los datos contenidos en el banco de datos sobre los desplazados de guerra en San Pablo, consolidado por Salles et al. (2013). La investigación reveló que la política brasileña de admisión a los desplazados de guerra como mano de obra industrial tuvo un impacto directo en el perfil de la población rusa seleccionada para inmigrar al país, la cual se dirigió predominantemente a la capital paulista. Los refugiados rusos llegados de China presentaron un perfil demográfico y social distinto, con evidencias de una mayor proporción de mujeres y niños y empleada en el sector de servicios. Las características profesionales de los dos grupos determinaron su distribución por los barrios de San Pablo. Mientras los desplazados de guerra de Europa se dirigieron a los barrios periféricos e industriales, los rusos provenientes de China se instalaron en los barrios más cercanos al centro de la ciudad.

Palabras clave: Desplazados. Rusos. Posguerra. San Pablo. Inmigración.

Recebido para publicação em 10/08/2017

Aceito para publicação em 27/10/2017 